really entail a journey of four miles from doctor's residence to patient's, a state of affairs that could only normally exist once it is determined that carrying coals to Newcastle is a vital principle of economics, he will perhaps realize that his rural colleagues who have a list of between 1,000 and 1,500 with no hope ever of increasing it, but which nevertheless entails the same working hcurs as an urban doctor with a list of around 4,000, rely on the mileage fund these days for about $40 \%$ of their income, and are very jealous of encroachment upon it by their urban neighbours.-I am, etc.,

Ingham, Lincoln.

S. WRAY.

\section{The Public Health Award}

SIR,-Dr. C. Metcalfe Brown, chairman of the Public Health Committee, is quoted in the Supplement of June 23 (p. 283) as saying that the Darlington motion, "In the event of any authority having failed to implement in full the award of the Industrial Court ... by September 1, 1951, the matter shall be referred to the Minister of Labour, and in the event of full implementation not being obtained the British Medical Association shall take action, and advise medical officers employed by the defaulting authorities to withdraw their service," would not be helpful at the moment. It would be helpful in that the Minister of Labour would have to appoint a Tribunal, which could hardly fail to endorse the award of the Industrial Court, which would then have the force of law. I challenge Dr. Metcalfe Brown to name an effective alternative.

$\mathrm{He}$ is also reported as stating that they would not know by September 1 how many authorities had implemented the award. Why not, and when will they know? It should not be beyond the capabilities of the staff of the Association to obtain this information from the chief medical officer of each authority. Where there is a will there is a way, but is the will there when the concern is the welfare of a relatively small number of medical officers?

Apart from the inequity which gave assistant medical officers an increase of $64 \%$ at maximum over pre-war salary compared with $111 \%$ for all adult male workers and $184 \%$ for miners, the British Medical Association should never have accepted the award of the Industrial Court, for by so doing it condoned the divorce of public health medical officers from the remainder of the medical profession in relation to salary awards and relegated them to the status of employees of local authorities.

I refer to the award of the Industrial Court being retrospective to October 1, 1950, while the awards to all other branches of the profession are to July $5,1948$.

The majority of full-time public health medical officers are in the assistant medical officer grade, yet so far as I know there is no assistant medical officer on the Public Health Committee. This large body must have representation. We must start now to organize for a revision of the award, which must contain provision for a senior clinical medical officer grade with comparable emoluments to senior administrative departmental officers ; otherwise the knell of clinical preventive medicine has been sounded.

We in County Durham foresaw the writing on the wall and organized the Durham County M.O. Guild, a small but militant body with twenty-nine members, which has been instrumental in carrying out the Association's policy without fear of personal consequences. We feel that a more vigorous approach is needed to the problems that confront public health medical officers than that pursued by the Public Health Committee. I should be grateful if those who think along similar lines would get in touch with me with a view to obtaining representation and control of the conditions of our service.-I am, etc.,

Bishop Auckland. Co. Durham.

Maurice B. Griffith, Hon. Sec., Durbam County M.O. Guild.

*** The Secretary of the Association states: Some places on the Public Health Committee have yet to be filled for the coming session, and both the Committee and the Society of Medical Officers of Health have in mind the desire for representation of all sections of the public health medical services. As to awards of increased remuneration to other branches of the profession, not all have been retrospective to July $5,1948$.

\section{Reconsider Immediate Arbitration}

SIR,-I would invite the General Medical Services Committee to reconsider its decision to seek immediate arbitration on the remuneration question until it has obtained a definite answer from the Minister whether or not he definitely rejects the recommendations of the Spens Committee in this regard. By implication, the Minister's letter of May 23 seems to embody such rejection, but a definite answer yes or no should now be sought. The week taken to obtain such an answer would be of no moment at this juncture. The profession should not be jockeyed into hasty decisions at this late date after years of delay. Too many hasty answers have been called for from the rank and file in the past, and they are responsible for our present impossible position. The tactics should not now be repeated.

I suggest, therefore, that such an answer be sought immediately and before any step is taken to initiate arbitration. In the event of an answer embodying the Minister's refusal to implement Spens now, I can conceive of no circumrefance which would more strongly unite a now sadly divided and bewildered profession in concerted and decisive action against the evasive tactics with which we have been treated for some years past. Moreover, in the light of such refusal, our position would be immeasurably strengthened if resort to arbitration were subsequently taken, for we would come to arbitration as the victims of broken promises and bad faith. Likewise, our case would be further strengthened if the Minister reaffirmed acceptance of Spens, already voiced by his predecessors at the Ministry. An evasive answer could be taken as a rejection of Spens.

So great appear the tactical advantages to be derived from this suggested procedure, and so obvious do they seem, that I invite every practitioner to support it by immediate letter to the secretary of his local medical committee before the conference to be held on July 19.

I would like also to ask the G.M.S. Committee to consider the effect of its decision in rejecting outright that part of the Minister's proposal to apply $f 2 \mathrm{~m}$. to bettering the position of our colleagues with lists " of the order of 1,000 to 2,500." Acceptance of this forthwith, but without any strings attached and on account, as it were, would have tended to dispel the growing conviction among our colleagues who are -struggling in almost penury that the B.M.A. has no concern for their plight and is not trying to improve it as quickly as possible. This conviction is being voiced, and, unless it is immediately dispelled by action (not words), the rift in our ranks already brought about by the 1946 Act will be further increased, and an increasing demand for a salaried, wholetime service is to be feared from unestablished practitioners as well as from those already established but who are in dire economic need. This is a matter of no little urgency and its possibilities are serious. We cannot afford here to play into the Minister's hands.-I am, etc.,

Shrewsbury.

W. J. GRant.

Correction.-In the Supplement of June 2 (p. 219) we reported the case of a doctor who prescribed " marmite" for a patient. The local medical committee held that marmite was a food and not a drug for the purposes of prescription under the N.H.S., but the board of referees held that the doctor was correct in prescribing marmite as a drug in the circumstances of this case. We then erroneously stated that the Minister of Health upheld the doctor's appeal. In fact, in cases of this kind the decision of the referees is final. The Minister is entitled to put a case to the referees, but there is, no question of his upholding the appeal. The procedure is laid down in Regulation 16 of the National Health Service (Service Committees and Tribunal) Regulations, 1948. 